\title{
O historiador da arte como colecionador de vestígios - Aby Warburg e a ciência da cultura
}

\author{
Wanderson Barbosa dos Santos
}

\section{RESUMO}

A obra de Aby Warburg (1866-1929) representa um marco importante para o campo da história da arte, sobretudo, ao aproximar a ciência da arte com a antropologia visual, sociologia da arte e a história num complexo conceito de ciência da cultura. Assim, como historiador da arte, Warburg propõe a questão da transmissibilidade de valores da Antiguidade a partir do seu conceito de vida-póstuma [Nachleben]. O presente artigo pretende analisar o dilema e as consequências do legado intelectual de Warburg tomando como base as ideias de vestígio e continuidade da Antiguidade. Nessa perspectiva, mostraremos através da análise da pintura italiana de Botticelli, a arte dos índios Pueblos da América do Norte e a escultura de Laocoonte a "sobrevivência" das imagens e símbolos da antiguidade adotando como referencial teórico as análises de Warburg sobre a ciência da cultura.

Palavras-chaves: Imagens; Vestígios; Continuidade histórica; Teoria da Cultura; Antiguidade.

\section{ABSTRACT}

The work of Aby Warburg (1866-1929) determine an important advance in the field of art History, above all bringing art science closer to visual anthropology, sociology of art and history in a complex concept of the science of culture. Thus, as an art historian, Warburg proposes the question of the transmissibility from Antiquity from this concept of posthumous-life [Nachleben]. The present article intends to analyze the

${ }^{1}$ Doutorando em Sociologia pelo Programa de Pós-Graduação em Sociologia da Universidade de Brasília - UnB, pela linha de pesquisa Teoria e pensamento social. E-mail: wanderson_santos@outlook.com. 
dilemma and the consequences of the intellectual legacy of Warburg taking as base the ideas of vestige and continuity of the Antiquity. From this perspective, we will show through the analysis of Botticelli's Italian painting, the art of the Pueblos Indians of North America and the Laocoon sculpture, the "survival" of the images and symbols of antiquity, adopting Warburg's analysis of the science of culture as a theoretical reference.

Key-words: Images; Vestiges; Historical continuity; Theory of Culture; Antiquity.

$\mathrm{O}$ ritual das serpentes dos índios Pueblos, a obra-prima da pintura italiana O nascimento de Vênus (1485) de Sandro Botticelli, a Morte de Orfeu (1494) de Albrecht Dürer e Le Déjeuner sur L’herbe (1862-1863) de Édouard Manet são apenas alguns exemplos da erudição e versatilidade intelectual dos ensaios produzidos pelo historiador da arte e teórico alemão Aby Warburg (1866-1929). Sua reflexão é transcendente no sentido de que rompe com as limitações impostas pela dita especialização das ciências modernas. Dotado deste atributo, ele percorre as produções da arte desde a "Antiguidade pagã" até os desdobramentos da pintura moderna europeia analisando, sobretudo na pintura italiana, a sobrevivência de vestígios que permaneceram no tempo. A intepretação de Warburg reconhece e destaca o desenvolvimento histórico do estilo, mas, no entanto, reitera a perenidade, traduzida nas formas que existem na contemporaneidade das "assombrações", isto é, os vestígios que permaneceram em sua vida póstuma, a saber, no conceito de warbuguiano de Nachleben. ${ }^{2}$ No meiotempo entre o que Warburg chama de antiguidade pagã e a

\footnotetext{
${ }^{2}$ Acompanho a sugestão de Leopoldo Waizbort (2015) a respeito da tradução de Nachleben como vida-póstuma. Conforme observaremos ao longo deste texto a ideia de Warburg aponta para a permanência de elementos da antiguidade nas expressões artísticas do renascimento italiano. O ponto é, então, observar as permanências de significados do passado renovados no presente.
} 
modernidade haveriam elementos que sobreviveram de modo intemporal. A análise da história da arte, sob este ponto de vista, permitiria ao investigador observar a sobrevivência através de vestígios do passado, especialmente na produção de símbolos e de imagens.

Para melhor compreensão dos atributos pelos quais a configuração warburguiana da história da arte perpassa, a ideia deste ensaio é: problematizar a posição de Warburg a respeito da ideia de ciência da cultura, comparando-a e mostrando seus potenciais heurísticos, especialmente, quando combinadas com as ideias de vestígio e continuidade histórica. Assim, utilizando estas categorias, proponho uma discussão sobre a interdisciplinaridade do conhecimento em Warburg e seu aproveitamento de leituras oriundas de outros campos disciplinares como a antropologia, história e sociologia para sua Kulturwissenschaft. É, precisamente na combinação entre reflexão sobre arte e a antropologia que destacaremos a proposta de Warburg de compreensão da ciência da cultura, analisando vestígios e detalhes na arte. Neste sentido, ao longo do texto apresentaremos algumas imagens que ilustram o procedimento warburguiano de interpretação da arte.

Como aludimos, a hipótese histórica de Warburg é a da presença de vestígios das culturas da antiguidade em produções artísticas distanciadas tanto temporalmente, quanto geograficamente, isto é, ele propõe uma análise teórica que pressupõe tanto a transmissibilidade da cultura, em símbolos, imagens e na memória, como sua própria difusão no tempo. O autor chama a permanência (ou sobrevivência) de Nachleben, algo próximo da ideia de vida póstuma. Lembremos o que a etimologia da palavra vestígio nos orienta no encaminhamento da questão. Vestígio significa: deixar sinais. Em Warburg esses sinais são vistos ao longo da história e oscilam em diferentes povos e numerosas culturas de forma a cruzar as fronteiras do tempo e questionar as noções de pertencimento e circulação simbólica. O modo da circulação desses 
símbolos ainda nos parece misterioso, afinal, quais seriam as conexões culturais entre os índios Pueblo da América do Norte e sua ritualística com as serpentes e a figura grega de Laooconte e seus filhos? Destacaremos ao longo do texto como Warburg tenta resolver este problema apontando a emergência da análise da imagem como caminho para a reflexão. No entanto, retomando ao caminho deixado pela etimologia do termo vestígio, podemos, sabendo que Warburg leu atentamente a obra de Charles Darwin, propor uma conexão entre os dois. Como forma de ilustração da ideia, assim, o que na teoria evolutiva emerge como a sobrevivência de órgãos vestigiais, no sentido darwinista, Warburg acolhe a análise dos vestígios reinformando-a numa discussão das práticas culturais, a saber, perseguindo a presença de significados que permaneceram em representações simbólicas e imagéticas. Se Warburg interpreta a cultura a partir de sua evolução das formas do paganismo primitivo, passando pelo paganismo clássico e com a culminação em sua expressão moderna, os vestígios do passado são absorvidos, na medida que, são parte do próprio processo de desenvolvimento sociocultural. Os vestígios reaparecem, ao passo que, são parte constitutiva de uma memória socialmente compartilhada. Por essa via, as manifestações de cultura como a pintura, dança, ornamentação em cerâmicas, símbolos e religião incluem-se num movimento mais amplo de simbiose de desenvolvimento histórico cultural. Nesse sentido, o compartilhamento de símbolos de culturas, na leitura de Warburg, sugere uma própria lógica de difusão e transmissão de representações partilhadas no tempo e no espaço.

Num livro notável, Didi-Huberman utilizou a ideia Wargurg de Nachleben der Antike [Sobrevivência da antiguidade] para salientar a ampliação filosófica promovida por Warburg nos caminhos da história da arte contemporânea. Nesse sentido, tempo e imagem combinam-se na leitura warburguiana como somente um corpo, de modo que, o 
historiador da arte, orientado sob esta perspectiva, identifica os "fantasmas" que sobrevivem na arte. De acordo com Didi-Huberman (2009) apesar do caráter essencialmente histórico das manifestações de cultura, em Warburg, há um impulso geral pelo questionamento da territorialização de uma análise puramente histórica, visto que, as imagens são resultadas de movimentos dinâmicos que seriam apenas provisoriamente “cristalizados”. Nesse sentido, na leitura do autor, Warburg propõe uma história da arte [Kunstgeschichte] alimentada por um conceito de tempo complexo, isto é, um conceito de tempo entendido metodologicamente como "provisório" e "dinâmico": "Ele significa, para dizer com clareza, que o tempo da imagem não é o tempo da história geral, esse tempo que Warburg descobre aqui através das 'categorias universais' de evolução.” (DIDI-HUBERMAN, 2009, p. 35).

O acento sobre as ideias de "categorias universais" e "evolução" decorre do entendimento antropológico de Warburg a respeito de uma sincronia civilizacional entre as culturas. Em certa medida, podemos ler parte de suas observações como sustentadas pela antropologia evolucionista, ${ }^{3}$ sobretudo de Tylor, no entanto, o entendimento sobre a evolução foi aprimorado e problematizado com a leitura da obra de Lucien Lévy-Bruhl (2008). Warburg evoca a ideia de Lévy-Bruhl de loi de participation como uma "característica das funções anímicas dos homens primitivos." (WARBURG, 2005, p. 303). Sabe-se que, para Lévy-Bruhl, as funções mentais dos "primitivos" são muitas vezes pautadas na ideia de causalidade, assim, não são necessariamente, sustentadas pela lógica do

3 Recorrendo novamente ao trabalho de Didi-Huberman (2009), cabe destacar, que há uma aproximação entre as reflexões de Aby Warburg, sobretudo a respeito da discussão sobre a cultura "primitiva” e a civilização com as reflexões antropológicas de Tylor, autor conhecido por sua perspectiva antropológica pautada no evolucionismo cultural. Nesse sentido, Didi-Huberman esclarece que, ao exemplo do conceito de "sobrevivência", utilizado por Warburg para enfatizar as conexões entre as diversas culturas, foi, inicialmente, instrumentalizado pela antropologia inglesa na qual Tylor fazia parte. Em inglês a Nachleben recebe os contornos do conceito de "survival" que, segundo Didi-Huberman, o próprio Warburg escreve em certas ocasiões na língua inglesa. 
raciocínio da humanidade ocidental. Ainda segundo a análise do autor, as diferentes mentalidades se posicionam no mundo mobilizando, a partir das realidades socioambientais, racionalidades "localizadas", ou seja, abre-se espaço a partir deste argumento para a compreensão sociogênica do pensamento baseado num conceito multilinear de desenvolvimento. Assim, os diferentes caminhos percorridos pela civilização europeia e a "primitiva”, segundo Lévy-Bruhl são alicerçados por essas distintas lógicas localizadas de desenvolvimento cultural das mentalidades (LÉVY-BRUHL, 2008).

Entre Tylor e Lévy-Bruhl, Warburg vislumbrou duas maneiras de compreensão antropológica. ${ }^{4}$ Por um lado, tomando o conceito de sobrevivência, por outro, constatando uma ideia mais ampla de desenvolvimento humano a partir das influências socioambientais. No tratamento da investigação sobre a história da arte, Warburg considerou ambas perspectivas antropológicas, especialmente por julgar os elementos antropológicos e psicológicos contidos nas análises dos autores como fundantes para uma compreensão da vida póstuma das imagens. Os vestígios que renascem na ciência da cultura de Warburg aparecem, como preocupação do historiador da arte, especialmente, na estilização da linguagem artística. Antes de avançarmos para outra parte da reflexão, é lícito demonstrarmos, apenas no âmbito de uma análise teórica do legado intelectual de Warburg o conjunto de influências importantes para a compreensão da obra do autor. Esse movimento, objetiva unicamente enfatizar o caráter interdisciplinar de sua teoria da cultura, uma vez que, antes as já citadas influências da biologia de Darwin, a antropologia de Tylor, devemos lembrar, uma influência

\footnotetext{
${ }^{4}$ No sentido de uma complementação da constelação de leituras decisivas para a produção intelectual de Aby Warburg, apenas lembremos, para além de Tylor e Lévy-Bruhl, o diálogo do autor com o antropólogo Franz Boas. A questão da circulação de símbolos culturais foi debatida entre Warburg e Boas em algumas correspondências. É evidente que parte de suas considerações sobre antropologia deriva de reflexões tomadas anteriormente por Boas em outras ocasiões.
} 
filosófica decisiva. Warburg aceitou a tradição nietzschiana ao trabalhar a cultura por meio da tensão permanente entre impulsos apolíneos e dionisíacos. A dualidade orienta a teoria histórica de Warburg sobre o reaparecimento da antiguidade no processo de civilização humana, a saber:

Desde os dias de Nietzsche, não é mais necessária uma atitude revolucionária para visar a essência da Antiguidade no símbolo de uma herma dupla como Apolo e Dionísio. Pelo contrário: o uso rotineiro e superficial dessa teoria dos contrários para observar as formas de arte pagã antes dificulta o esforço sério em conceber a sofrósina e o êxtase, na unicidade orgânica de sua função polar, na definição dos valores limítrofes da vontade expressiva humana (WARBURG, 2015, p. 368-369).

A seguir, destaco algumas considerações sobre o reaparecimento dos vestígios do passado enfatizando os estudos sobre a história da cultura de Warburg com olhar especial para a reflexões sobre arte na Renascença e o ensaio sobre os índios Pueblos. Nesse sentido, o procedimento adotado neste artigo é a análise dos textos warbuguianos que apresentam a reflexão a respeito da permanência do passado, demonstrando, através da análise de imagens, os vestígios da antiguidade destacados pelo autor. $\mathrm{O}$ contraponto entre imagem e texto, adotado aqui, circunscreve e subsidia a análise teórica da obra de Warburg.

\section{Warburg como colecionador de vestígios}

Se até aqui acompanhamos os contornos gerais da teoria da cultura de Aby Warburg que, como vimos, retoma categorias advindas da teoria da evolução da cultura e a metamorfoseia dentro de uma nova razão histórica através da valorização da imagem e do símbolo, recupera uma perspectiva de sobrevivência das formas e suas correspondências ao 
longo da história humana. Em alguns textos essa ideia aparece como sobrevivência da antiguidade, já em outros, como vida póstuma da Antiguidade pagã. ${ }^{5}$ A contribuição de Warburg é decisiva para compreendermos na investigação antropológica os "vestígios" daquilo que sobrevive e permanece. Devido à condição, evidentemente, abstrata da ideia, apresentemos as constatações de Warburg tomando como subsídio suas pesquisas antropológicas e iconográficas sobre arte.

Se considerarmos os meios de representação humana no sentido amplo, adentraremos ao problema que Giorgio Agamben (2015) apresentou a respeito do legado intelectual de Warburg ao caracterizá-lo como precursor de uma ciência sem nome. Nessa medida, é justamente por conta do que apontamos antes a respeito da constelação de disciplinas do conhecimento que foram mobilizadas por Warburg em suas diversas pesquisas, que temos dificuldade de atribuirmos uma definição totalmente segura de sua atuação sem incorrermos no risco de mutilar ou limitar o seu potencial científico. Warburg, em muitos escritos, apresentava-se como historiador da arte, no entanto, essa definição, mesmo sendo auto atribuída, parece ainda mitigar a contribuição do seu trabalho em áreas como a antropologia, psicologia e o estudo do símbolo e da imagem.

Agamben (2015) procura demonstrar que a ciência preconizada por Warburg existe, porém, ainda não tem nome, ou seja, a condição

5 Seria importante precisar o que Warburg compreende com os termos Antiguidade, Antiguidade pagã ou Antiguidade primitiva. Porém, o autor não se dedica durante seus ensaios a uma definição exaustiva e finalizada do termo, evitando assim, justamente um esgotamento teórico e imobilização ou engessamento do termo. Aduzimos que a ideia de Antiguidade e suas variantes surge a partir da oposição com o conceito de modernidade europeia, na qual estava inserido Warburg, sendo o paganismo manifestações culturais não cristãs. $O$ paganismo ou as manifestações primitivas colocam-se sempre no "passado" que, de acordo com a tese do autor, passado que permanece. Essa leitura deriva da concepção de evolução utilizada em suas pesquisas em que Antiguidade primitiva, Antiguidade clássica e modernidade são formas que sintetizam longos períodos históricos em sua ciência da cultura. Sendo assim, vale ressaltar, que de modo algum Warburg defende que a Antiguidade ou o paganismo sejam oposições à cultura. 
singular de sua produção intelectual demonstra uma originalidade que dificilmente pode ser captada pelas delimitações da ciência moderna. Em Warburg as fronteiras que delimitam as formas de conhecimento são suspensas numa perspectiva de análise totalizante do fenômeno da arte. Nesse sentido, o entrelaçamento da proposta para a investigação entre a antiguidade e a modernidade sugere, antes de mais nada, um nexo inescapável entre a intenção de historiador da arte com as contribuições antropológicas de seu contexto histórico. A posição pioneira outorga um problema permanente para a ciência, na medida que, para Warburg nem a iconografia, nem a antropologia e nem mesmo a história da arte no sentido estetizante [ästhetisierende Kunstgeschichte] são fins em si mesmos, ou seja, toda expressão de cultura deve ser compreendida no seu processo. Agamben retoma que a ideia de processualidade ao assumir seu maior efeito com o conceito de Nachleben.

Se Warburg pôde mesmo apresentar o problema do Nachleben des Heidentums, da vida póstuma do paganismo, como seu problema supremo de estudioso, é porque ele tinha compreendido, com uma surpreendente intuição antropológica, que a questão da 'transmissão e da sobrevivência' é o problema central de uma sociedade 'quente' como a ocidental, obcecada pela história a ponto de querer fazer o próprio motor do desenvolvimento (AGAMBEN, 2015, p. 117).

Dentro do âmbito da sobrevivência da cultura, Warburg foi inovador ao aproximar a pintura italiana do Quattrocento com concepções da Antiguidade. Nessa condição excepcional, as pinturas de Botticelli como O nascimento de Vênus (1485) e A primavera (1477-1482) são lidas na correspondência entre imagem, poesia e literatura. Tratavase, portanto, de compreender em que medida haviam possibilidades de transmissão de elementos do passado para o presente, com olhar especial para as dimensões da transmissibilidade na dimensão da representação artística. Sua contribuição teórica foi demonstrar a 
cristalização de significados nas imagens que mesmo sendo manifestações simbólicas de culturas determinadas, sob o prisma do reconhecimento do vestígio, se conectam na continuidade histórica.

Warburg se dedicou em suas pesquisas sobre pintura italiana entender em que medida sobreviveram, na estética italiana, elementos pertencentes a Antiguidade clássica. É na ligação entre Antiguidade e Renascimento que as obras de Botticelli mostram-se como representativas do movimento de transmissão dos vestígios do passado e infiltram-se no presente. Em sua tese de doutorado entregue à Universidade de Estrasburgo, Warburg (2015) investiga como nas pinturas de Botticelli (as já mencionadas anteriormente: O Nascimento de Vênus e A primavera) carregam consigo concepções pertencentes ao passado da Antiguidade e permaneceram na pintura do primeiro Renascimento. Podemos imaginar o procedimento de montagem através das palavras do texto: a pintura de Botticelli, munida de influências da poesia homérica e de Poliziano, aponta para um interesse do artista de corresponder em sua obra parte da literatura poética do seu tempo. Por outro lado, na avaliação de Warburg, Botticelli, para além das fontes da antiguidade grega, recupera como fonte a obra poética contemporânea ao seu tempo de através dos escritos de Angelo Poliziano, poeta de Florença. Reside aqui um primeiro traço de singularidade do exame warburguiano, pois, se, para a realização de uma história da cultura é preciso recorrer ao conjunto de influências que precisam ser interpretadas através de vestígios, a história da arte, deveria retomar elementos não somente das outras artes, mas, sobretudo, de outras ciências. Warburg menciona que a relação entre a pintura de Botticelli e a poesia de Poliziano marcou a "evidência" para o entendimento mais amplo dos limites e contornos dessa ciência que, em seu ponto de vista, não deveria se apegar a uma visão puramente iconográfico: 
Em toda uma série de obras de arte próximas umas das outras pelo seu tema: na pintura de Botticelli, no poema de Poliziano, no romance arqueológico de Francesco Colonna, no desenho feito no círculo de Botticelli e na descrição que Filarete fez de uma obra de arte - em todos esses casos, fazse presente a inclinação (formada com base no que então se sabia da Antiguidade) em recorrer às obras de arte da Antiguidade, quando se tratava de dar corpo à vida em movimento (WARBURG, 2015, p. 49).

A arte transborda a moldura do seu núcleo interno de significados. Ela tanto pode ser iconográfica como também histórica, sociológica, antropológica e todas essas abordagens podem estar reunidas numa unidade arquitetada pelo pesquisador da cultura. $\mathrm{O}$ todo, sempre, mantém-se em comunicação com as partes. Em sua radicalidade, a crítica manifestada pela ciência sem nome de Warburg, direciona-nos para o problema de investigação da arte relacionado a interpretação dos vestígios. O próprio autor identificou um novo movimento iconográfico a partir da pintura $O$ nascimento de Vênus. E é justamente a palavra "movimento" presente nos trajes e na disposição corporal de Vênus que refletem a "inspiração" da poesia de Poliziano que, no caso, remetem a modelos da Antiguidade Clássica. ${ }^{6}$ Warburg foi o primeiro a notar no detalhe do "movimento" sugerido por Botticelli estariam justapostos elementos da Antiguidade e da contemporaneidade italiana do Renascimento.

Na tela, a deusa exibe seus cabelos esvoaçantes, seu joelho levemente dobrado também alude a alguma espécie deslocamento. A ação de movimento é um desdobramento do sopro de Zéfiro, Deus dos ventos do Oeste, que se situa na parte esquerda do quadro. No rosto de Zéfiro, o pintor sugere a realização de um esforço para a ação do sopro, pois, através de sua boca lança-se um filete de vento que movimenta uma pequena rajada de vento e algumas flores na direção de Vênus. No

\footnotetext{
${ }^{6}$ Atentei-me ao detalhe do movimento da obra $O$ nascimento de Vênus através das observações de Aby Warburg sobre a mesma pintura.
} 
lado direito da tela uma Hora segura uma manta vermelha adornada com flores que na pintura seguem o movimento de tremulação com o vento soprado pelo Deus dos ventos do oeste. No conjunto, são inúmeras as referências internas a pintura que remontam ao movimento. Todas vestimentas utilizadas pelas personagens estão, sugestivamente, inclinadas na direção oposta ao movimento do vento. $\mathrm{O}$ mar, situado no segundo plano da pintura, pela forma e a disposição das ondas, realiza o movimento de espiral que sustenta a concha na qual Vênus realiza seu nascimento. Considerando os detalhes destacados, nota-se que o pintor procurou caracterizar sua representação do nascimento da deusa reavivando uma estrutura de movimento que se inscreve no corpo e na natureza da cena.

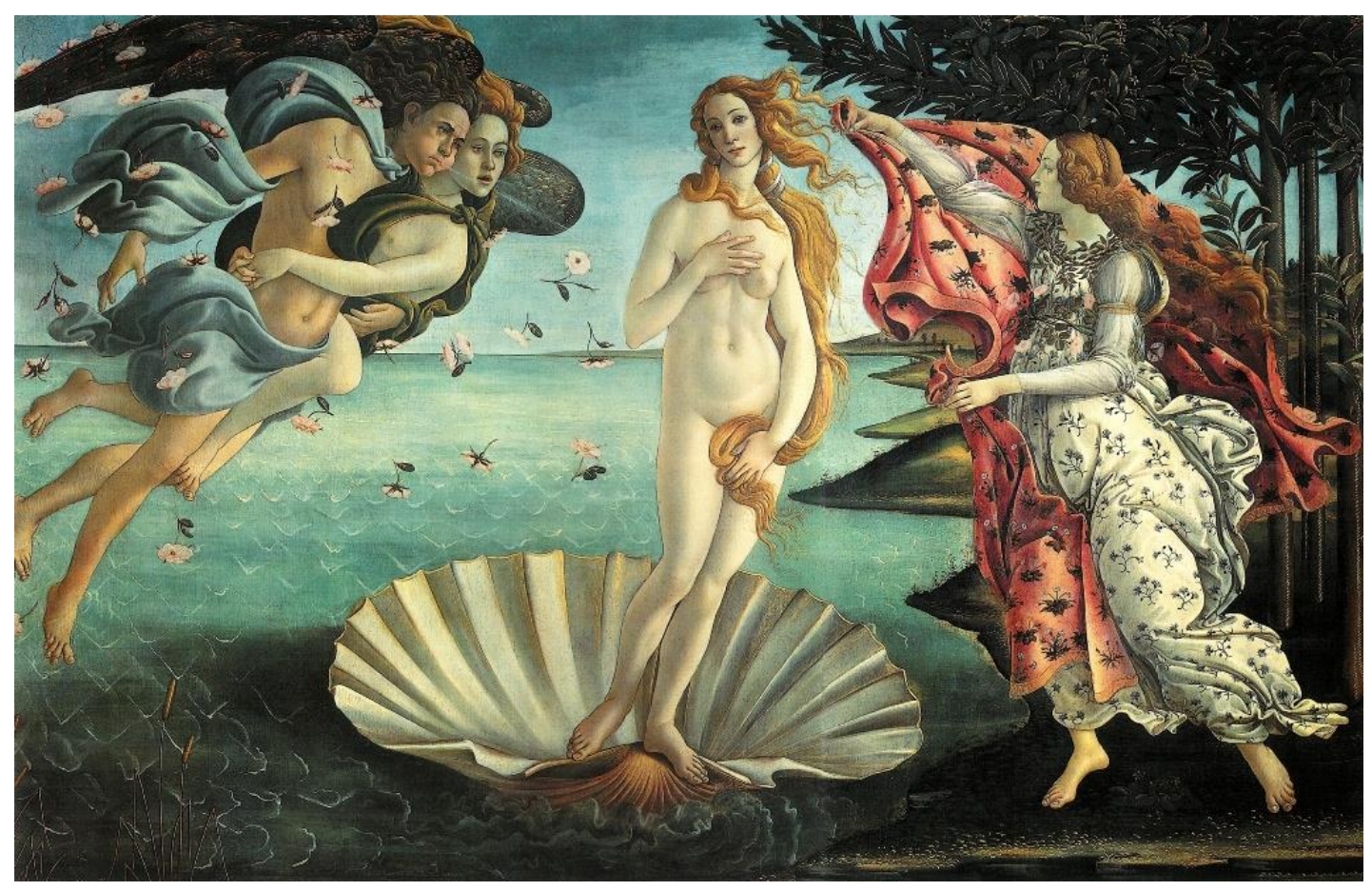

Figura 1 - O nascimento de Vênus, de Sandro Botticelli (1485).

Na poesia de Poliziano, de acordo com Warburg fortemente orientada pela poesia da Antiguidade, o movimento da Deusa é disposto de forma semelhante ao representado na pintura por Botticelli. No caso 
de Primavera que na poesia de Poliziano "expõe seus louros cabelos à brisa / e ata mil flores na pequena guirlanda”, ilustra a ideia de dinâmica presente no quadro do pintor italiano. ${ }^{7}$ É interessante notar a questão da transmissão presente no caso da pintura de Botticelli. Estendendo a questão sob o viés do pensamento de Warburg, pode-se observar o reavivamento de conteúdos da Antiguidade clássica que "ressurgem" na primeira fase do Renascimento italiano. Warburg (2015) observou a questão que apresentamos sobre a transmissibilidade de elementos da Antiguidade para o Renascimento apreciando os vestígios deixados nos detalhes das obras. Assim, a apreciação do movimento dos cabelos e o leve movimento dos joelhos da Vênus, o manto trêmulo segurado pela Hora na recepção de deusa e o sopro de vento de Zéfiro foram para Warburg essenciais para sustentar o apoio da pintura em modelos antigos (WARBURG, 2015, p. 27).

Em princípio, a observação dos vestígios presentes na pintura botticelliana são vistos à luz de relações biográficas e históricas. Warburg, nesse sentido, coloca em prática sua perspectiva de compreensão da arte como um fenômeno ligado à história da cultura no sentido mais amplo. No texto dedicado a Sandro Botticelli (2005), ele sugere que a compreensão da presença de Botticelli nos círculos de poder contemporâneos a ele, permitiu ao pintor, rivalizar com outros artistas de sua época e destaca que nessa leitura biográfica há indícios importantes a serem seguidos para uma interpretação da arte italiana. Poder-se-ia pensar que, tanto a relação entre o artista e a burguesia florentina, quanto o conhecimento de Poliziano sobre a Antiguidade

\footnotetext{
${ }^{7}$ Nos ensaios O nascimento de Vênus e A primavera de Sandro Botticelli [1892] e em Sandro Botticelli [1898], Warburg declara explicitamente que o pintor tomou como referência a poesia de Poliziano como "mediação" entre o Renascimento e a Antiguidade. Nesse sentido, a sobrevivência dos elementos da Antiguidade no primeiro Renascimento italiano ganha corpo a partir de um conjunto de referências advindas da expressão poética. O modo como Poliziano "aconselha", de certo modo, alguns caminhos pintura de Botticelli aduz a concepção mais ampla que Warburg defendia sobre a ideia de investigações no âmbito da história da arte.
} 
aludem a um determinado caminho de interpretação da pintura de Botticelli $^{8}$. Warburg sustenta que ali haviam "forças que impulsionaram e mantiveram esta transformação estilística”, ou seja, a metamorfose estética, de modo mais fidedigno a observação de Warburg, foi resultado de transformações históricas que, como não existem seres fora da história, o artista se vê situado nesse movimento de desenvolvimento (WARBURG, 2005).

A noção de transmissibilidade da antiguidade foi a fonte originalidade das observações de Warburg sobre o Renascimento. Ao mesmo tempo, o enigma da transmissão da cultura, no sentido que designa uma retomada de valores do passado, mostra-se como um leitmotiv da ciência da cultura warbuguiana. Afinal, os vestígios da Antiguidade que reaparecem no Renascimento são, resguardando as diferenças culturais entre as duas pesquisas, semelhantes no que diz respeito às questões observadas no ensaio Imagens da região dos índios Pueblos na América do Norte de 1923. A conexão entre temporalidade e a reflexão estética arregimentam o exame da cultura artística a partir da reunião de vestígios, eles podem tanto informar o historiador da cultura quanto sobreviver como fonte de expressão cultural na análise do autor.

Neste ponto, a posição intelectual de Warburg foi decisiva, posto que, em sua valorização das formas que se manifestam através dos vestígios, pôde, reconhecer o testemunho do passado na arte do Renascimento. $\mathrm{O}$ detalhe liga a Antiguidade pagã a arte do Renascimento e, sob este ângulo, sustenta a interpretação da Nachleben,

${ }^{8}$ Este é, sem dúvida, um elemento importante na interpretação dos textos de Warburg sobre a relação entre a Antiguidade e o Renascimento. Devemos notar que, a relação entre Botticelli e Poliziano, não se deu por um mero acaso. Ambos estavam inseridos nos círculos da burguesia florentina da época. Warburg relembra que Poliziano era um importante poeta naquele período e desempenhava papeis importantes na atividade cultural de Florença. Por outro lado, Botticelli, também gozava de prestígio, sobretudo a partir de 1481 quando foi convidado para realizar parte da decoração da Capela Sistina. Sendo essas características determinantes para a produção e disseminação cultural, Warburg propõe um tratamento da obra de arte a partir do conjunto de elementos presentes em seu contexto (WARBURG, 2005). 
isto é, do conceito de vida póstuma de Aby Warburg. No entanto, se levarmos em considerações as observações destacadas até aqui, a ideia de vida póstuma das formas ultrapassa até mesmo a própria concepção de sobrevivência e "ressurgimento". A implicação do conceito de Nachleben na teoria da cultura de Warburg possui como consequência interpretar a história da arte através de uma concepção singular de continuidade histórica.

Os espíritos do passado ressurgem na arte do Renascimento, mas, também, pairam nas manifestações artísticas e na memória social do homem moderno. Warburg advogava que no caso do Renascimento a continuidade se: "manifestava em uma reformulação estilística da aparência humana, por meio da mobilidade intensificada do corpo e no traje, pautada em modelo da poesia e das artes plásticas da Antiguidade.” (WARBURG, 2015, p. 99-100). Por essa via, Warburg sugere que há uma "infiltração" de valores do passado no movimento de estilo do Renascimento italiano, ou seja, nos detalhes das imagens, ele observou a continuidade de vestígios da Antiguidade clássica que foram apropriados em outro contexto histórico. $\mathrm{O}$ estilo se apoia na referência do antigo.

O alargamento do conceito de Nachleben, como Warburg pensa, se coloca na contramão de uma visão estreita do estudo da história da arte. Como dissemos antes, ele não se condiciona as limitações da especialização das ciências modernas, ao contrário, explora campos do saber histórico, estético e antropológico com o objetivo de remontar o enigma da sobrevivência e continuidade de elementos do passado na modernidade. $\mathrm{O}$ que nas observações sobre arte italiana, especialmente em Botticelli, emerge como vestígios de representações da Antiguidade pagã, em outros ensaios, como os dedicados aos índios Pueblos, Warburg como historiador da cultura, observa naquelas manifestações culturais algo próximo de uma representação do "paganismo vivo". Essa leitura deriva de uma inescapável visão evolutiva de Warburg que, no 
entanto, é mais complexa na medida que prevê um paralelismo [nebeneinander] entre as diferentes culturas.

Warburg, em sua análise sobre arte e a cultura dos índios Pueblos da América do Norte, reconhece, a possibilidade que se encontre ali, naquela região, fragmentos de uma cultura "primitiva" que não tenha sido "contaminada" pela modernidade. ${ }^{9}$ Em parte, essa expectativa deriva do caráter evolucionista da leitura do autor que, de modo sistemático, aponta na história três grandes momentos, a saber: o paganismo primitivo, paganismo clássico e a modernidade. No entanto, o tempo da história não determina a eliminação total do dito "primitivo", pois, o mesmo ainda "sobrevive" como fragmento da própria concepção de continuidade presente na ideia de Nachleben que, enfatiza as permanências, como formas e expressões de culturas antigas no tempo de agora. Também é esclarecedor notarmos que a pura descrição de um fenômeno sob a designação como pagão ou moderno, a partir dos textos de Warburg, em nada implica numa leitura qualificante ou desqualificante a julgar-se que: “o paganismo não é, em sua mentalidade, uma força hostil à cultura” (WARBURG, p. 251, 2015).

\begin{abstract}
No final, uma visada nas manifestações semelhantes do paganismo europeu deve nos levar à questão: em que medida essa visão de mundo pagã, tal como ainda sobrevive entre os pueblos, nos fornece um parâmetro para os processos de desenvolvimento que vêm do paganismo primitivo, passam pelo homem do paganismo clássico e chegam à modernidade? (WARBURG, p. 202, 2015)
\end{abstract}

\footnotetext{
${ }^{9}$ No ensaio sobre as Imagens da região dos índios Pueblos na América do Norte, Warburg associa a influência do "Catolicismo oficial" a contaminação da cultura dos índios Pueblos. Esta influência se deu pelo envio do governo americano de missões da igreja católica e a implementação de escolas na região. Comenta Warburg sobre o impacto dessa ação na cultura dos Pueblos: "Seu otimismo intelectual aparentemente teve êxito em fazer as crianças indígenas irem à escola em roupas adequadas e uniformes e deixarem de acreditar nos demônios pagãos. Isso é mesmo verdade para a maior parte das crianças assim educadas. Certamente pode ser um progresso. Mas se com isso se faz ou não justiça à alma dos índios, que pensa por imagens e está (como gostaríamos de dizer) ancorada na mitologia e na poesia, já é algo que prefiro não afirmar tão facilmente." (WARBURG, p. 249, 2015).
} 
A pergunta de Warburg prenuncia uma característica de seu método que procura as correspondências no passado e presente das manifestações de cultura. Assim, o que, inicialmente, chamou atenção de Warburg em sua pesquisa de campo com os índios Pueblos foi a relação ritualística presente entre o homem e a serpente. $\mathrm{O}$ ritual da serpente, descrito longamente em dois ensaios, evoca ao autor uma manifestação de cultura que se coloca num momento anterior ao da modernidade europeia. Sendo assim, no exame daquelas práticas ritualísticas, Warburg indica que poderia acessar uma dimensão da "vida psíquica” dos Pueblos. Embora pareça ser algo apenas de interesse antropológico, ele indica que, como historiador da cultura, o estudo de uma "humanidade pagã primitiva" conservada permite compreender a relação de unidade entre vida e magia. ${ }^{10}$

A partir daí, podemos levar adiante o seu procedimento e destacar como foram interpretados os vestígios que sobreviveram na história tomando como elemento de reflexão o caso dos índios Pueblos.

${ }^{10}$ A ideia warbuguiana de uma unidade e entre a vida e a religião assemelhase ao desenvolvimento posterior do tema da reprodutibilidade da arte na modernidade proposto por Walter Benjamin. O que em Warburg sugere como condição da sociedade "primitiva" ou da Antiguidade de relação total entre a arte e os conteúdos da vida, transpõem-se, num diálogo com Benjamin, na análise da emancipação da arte do culto religioso na modernidade. Não será possível desenvolver, aqui, este ponto a respeito da proximidade em relação a Benjamin, no entanto, proponho me dedicar mais profundamente sobre esse diálogo fundamental para o debate sobre teoria da arte em trabalhos posteriores. 


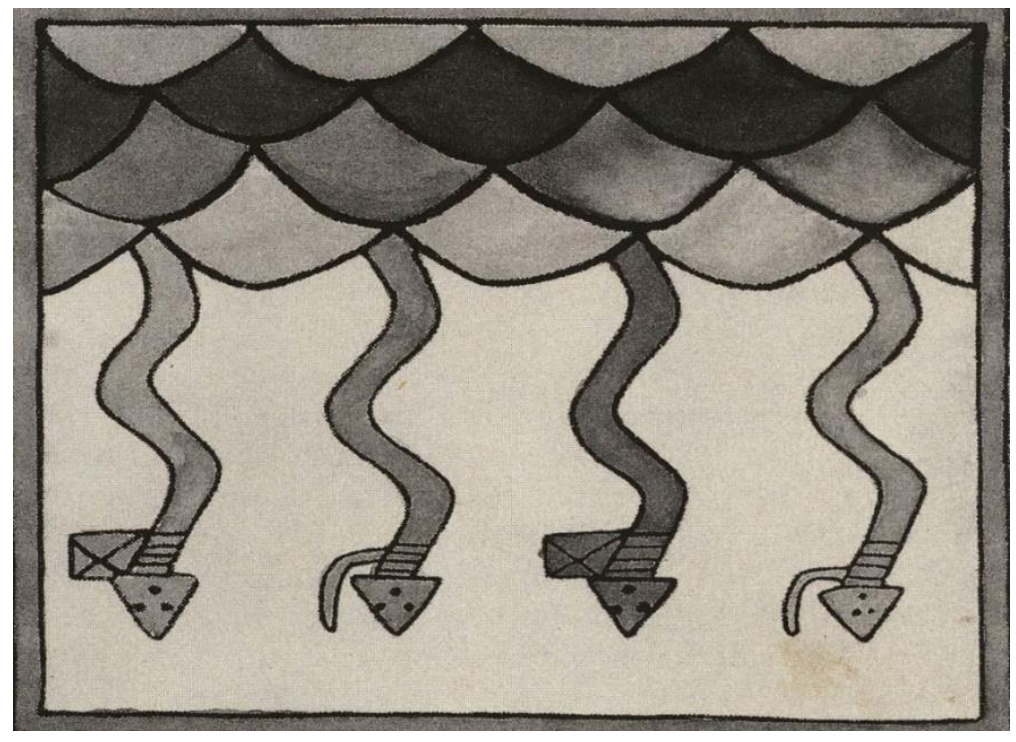

Figura 2 - Serpente como relâmpago. Reprodução de um piso de altar Kiva.

Nos registros das práticas culturais dos índios Pueblos, Warburg primazia a análise do estilo ornamental das imagens totêmicas, tanto por meio da documentação fotográfica, quanto também pelo registro de desenhos e reproduções de ilustrações daquela comunidade. A ação ritualística e a prática religiosa operam, na interpretação de Warburg, como indícios para a compreensão da "vida anímica dos índios”, ou seja, procura a partir de uma visão realista dos processos culturais entender o seu modo de operação e de produção de significados. Segundo essa visão apresentada, vale compreender os modos de representação da cultura em todas suas dimensões da vida como na arte, na religião, na história e na prática mágica. Os Pueblos, para Warburg, ao contrário do homem na modernidade, não autonomizaram a esfera religiosa das demais dimensões da vida o que, por um lado coloca-os nesse "estágio" visto como relacionado ao primitivismo pagão, mas, que por outro, faz com que suas práticas representem a conexão elementar entre natureza e cultura. É precisamente, a unidade entre religião e vida que permite a representação ritualística da natureza como uma unidade cultural, em determinado momento, diz Warburg: 
Pois enquanto as ferrovias não chegam, os povoados, a seca e a sede seguem levando às práticas mágicas que visam subjugar as tenazes forças da natureza - tais como as que aparecem por todo o mundo em culturas primitivas, pagãs e carentes de técnica. A seca ensina a fazer magia e a rezar (WARBURG, 2015, p. 201).

Se, pois, a religião e a magia primitiva pagã adentram a toda espécie de movimento de vida cultural, não é estranho notarmos que a própria simbologia e ornamentação ritualística reflita essa unidade. $\mathrm{O}$ paradoxo da relação em natureza e cultura, levando em consideração a interpretação de Warburg, mostra-se presente no ritual da dança com as serpentes. Warburg descreve que durante a cerimônia da serpente, os dançarinos e a serpente harmonizam-se como uma "unidade" que, no entanto, seus praticantes buscam por meio da relação de imitação da serpente a mediação com os elementos da natureza, no caso, a postulação pela chuva. A cerimônia com a serpente envolve as irmandades das aldeias Mokis que ocorrem em salas usadas para rituais religiosos e políticos chamadas de Kiva. Nas Kivas as serpentes são representadas nos ornamentos da sala, sendo destacadas por Warburg, a representação da serpente-raio. Durante a encenação da dança as serpentes são manipuladas pelos dançarinos de modo ritualístico. A conexão mágica entre os dançarinos e as serpentes unificam três dimensões da natureza: a chuva, o homem e o animal (WARBURG, 2015, p. 234-235).

Aqui os dançarinos e o animal vivo formam uma unidade mágica, e o surpreendente é que, nessas cerimônias de dança, os índios aprenderam a lidar com o mais perigoso dos animais, a cascavel, de modo a domá-la sem recorrer à força, a ponto de a criatura participar voluntariamente - ou pelo menos sem fazer uso de seus atributos predadores, se não for provocada - de cerimônias que se estendem por dias e que, nas mãos de europeus, certamente terminariam em catástrofe (WARBURG, 2015, p. 234). 
A serpente, mesmo que unida ao ritual de forma intrínseca, tem seu papel voltada a mediação com outros domínios da natureza, no caso, o animal conecta o homem a chuva: "Pois na dança da serpente em Walpi, a própria serpente é coagida a fazer tal mediação.” (WARBURG, 2015, p. 234). Como a própria dança com a serpente sugere, a mediação do ritual origina expressões culturais em outras dimensões, por exemplo, a representação da serpente aparece na ornamentação artística como no caso da decoração de cerâmicas e também no ornamento de templos religiosos dos Pueblos.

A cerimônia com as serpentes dos índios Pueblos, fornece para Warburg mais do que um retrato de uma prática pagã viva, ela simultaneamente redireciona sua atenção para os contornos de uma prática cultural que considera a unidade entre humanidade e natureza, como também, realça teoricamente a presença de vestígios culturais que tiveram uma vida póstuma na continuidade da história humana. O elemento que conecta a cultura dos Pueblos com a Antiguidade clássica, de acordo com Warburg, foi a serpente, visto que, como imagem e símbolo, sobrevive de forma intemporal.

Novamente, pode-se observar a questão do Nachleben, sobretudo, no que diz respeito à continuidade do símbolo da serpente nas mais diversas culturas, do Oriente ao Ocidente. Warburg defende os paralelismos entre a simbologia da serpente que, na tentativa de explicação do mundo, de modo geral, assume o papel de responsável pela representação da maldade no mundo. Na condição de criatura da natureza que representa as mazelas do mundo, a serpente, foi representada em diversas culturas como o ser responsável pela execução das punições divinas ou a encarregada pela sedução dos homens para o caminho da transgressão dos mandamentos sagrados. Nesse sentido, a representação da serpente como criatura da punição presente na 
escultura de Laocoonte e seus filhos e a presença da serpente na tradição bíblica, permitem a Warburg notar através do detalhe da presença da serpente a sobrevivência de uma temática comum entre culturas distintas. Encontram-se, nesse passo, um novo movimento de valorização da vida póstuma do detalhe, na medida que, elementos extremamente distantes espacialmente e temporalmente conectam-se a partir de algumas imagens socialmente compartilhadas.

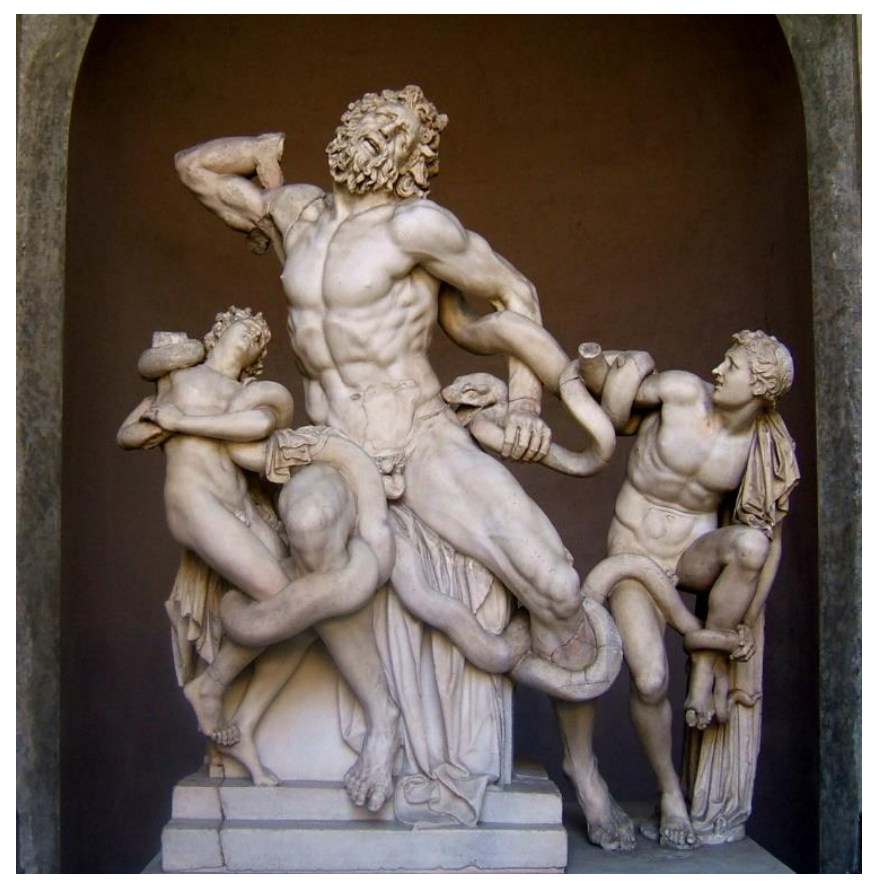

Figura 3 - Laocoonte e seus filhos. Escultura de mármore esculpida por Agesandro, Atenodoro e Polídoro. Atualmente encontra-se no museu do Vaticano.

Na escultura de Laocoonte a punição do deus Apolo se concretiza no envio de duas serpentes marinhas para a execução do sacerdote e de seus filhos. Laocoonte foi punido por tentar interferir na guerra de Tróia. Warburg defende que a escultura ajudou no fortalecimento da imagem da serpente como uma criatura de purificação através da punição que, sob esse ponto de vista, auxiliou na visão pessimista do animal no Ocidente. Diz o autor: 
A vingança dos deuses, que as cobras estranguladoras aplicaram ao sacerdote deles próprios e a seus dois filhos, levou, no conhecido grupo da Antiguidade, à incorporação ostensiva do máximo sofrimento humano. [...] A morte do pai e dos filhos torna-se assim símbolo da paixão antiga: morte por vingança, perpetrada por demônios sem alguma justiça nem esperança de salvação. Eis o pessimismo trágico e desesperançado da Antiguidade (WARBURG, 2015, p. 239).

De fato, esse significado da representação da serpente como a mensageira da vingança carrega um pessimismo que se desdobra na tradição bíblica. Com os índios Pueblos a serpente funciona como uma espécie de "mediadora" entre elementos culturais com a natureza, pois, tratar-se-ia de uma cultura que a natureza se colocava sinal de proximidade entre religião e vida. Na Antiguidade clássica as divindades tomavam uso da serpente para a execução de punições, ao passo que, a própria figura ligava-se a algo que inspirava o perigo e impiedade. ${ }^{11}$ Ademais, dado o caráter nocivo da serpente, a tradição bíblica retoma a figura da serpente como símbolo das ofertas do pecado. Warburg destaca que, a imagem da serpente na árvore do Paraíso restitui a ideia da antiguidade da serpente como "causadora do mal e do pecado". A referência ao detalhe da serpente, visto por Warburg como um vestígio da história, aparecem em imagens cotidianas em várias culturas. A popularização da tradição bíblica sugere o movimento de divulgação dessa imagem, sobretudo ao indicar a referência da serpente como a responsável pelos males acometidos no momento do pecado original: "Na árvore de Paraíso ela é - tanto no Velho como no Novo Testamento - o poder satânico que provoca toda a tragédia do homem sob o pecado original." (WARBURG, 2015, p. 244-245).

${ }^{11}$ A exceção ao ponto de vista pessimista anotado por Warburg a respeito da simbologia da serpente é a representação de Esculápio, deus da saúde, que apresenta como traço a serpente enrolada em um bastão como símbolo terapêutico. Comenta o autor sobre a divindade-serpente: "Pois a serpente não é apenas, como diriam os índios de Cushing a mordida fatal (consumada ou prestes a) que aniquila sem piedade, mas também se revela como corpo que abandona sua pele e segue subsistindo outra vez renovada - como que se despindo de seu invólucro." (WARBURG, 2015, p. 240). 
A circulação do símbolo com a expansão da tradição bíblica permite, numa tentativa de ampliação do argumento de Warburg, compreender e situar a sobrevivência do símbolo da serpente na cultura moderna, especialmente, analisando a retomada da referência dos poderes malignos e pecaminosos da mesma. Parte da ideia de continuidade das formas culturais contidas na ideia de Nachleben se volta a permanência do passado na memória do presente. No entanto, retomando o argumento central do ensaio, olhemos como o detalhe da figura das serpentes orienta a teoria da cultura de Warburg em todo seu movimento histórico. Afinal, o tema da serpente constitui parte das inquietações centrais da obra warburguiana tardia.

Uma característica básica congrega as diferentes tradições mencionadas, sejam elas ligadas ao denominado paganismo dos índios Pueblos ou das manifestações de cultura da Antiguidade clássica e a tradição bíblica que é a ideia de infiltração dos valores do passado e o ressurgimento de elementos, símbolos e expressões de culturas de modo intemporal. Nesse sentido, a atitude de Warburg é ambivalente, uma vez que, enquanto concede ao paganismo o elemento vivo de conexão entre religião e a vida também via em suas manifestações de vida artística um modo genuíno de resposta das questões existenciais e práticas através do vínculo entre natureza e cultura. Admitindo-se a historicidade de toda criação cultural, a Antiguidade clássica e a tradição bíblica retomam esse elemento estrutural, no entanto, o ressignificam. No processo de retomada do passado os símbolos passam por uma transformação, permanecendo na forma da tradição alguns vestígios ligados ao passado. $\mathrm{Na}$ arte italiana esses vestígios, segundo Warburg, estavam ligados à tradição da Antiguidade clássica. No caso dos índios Pueblos as referências ao paganismo primitivo avançam numa difusão cultural mais ampla. 
O elemento definidor que permite a Warburg detectar as permanências dos vestígios é a união entre a antropologia e a história da arte como campos disciplinares unificados. A análise antropológica dos índios Pueblos orienta o exame da arte como um fenômeno de ordenação de toda vida cultural, fortemente ligado a práticas cotidianas de explicação da vida. Assim, de fato, a simbolização da serpente está relativamente próxima de uma teoria que abarque os elementos de permanência em toda a história. Com os Pueblos a serpente captura e incluída no ritual atua como mediadora da unidade entre a homem e natureza, por outro lado, na tradição bíblica, a serpente foi posta como origem da maldade e primórdio do pecado, já na antiguidade clássica, a serpente, simboliza o papel do algoz dos deuses punindo e representando o sofrimento humano. Warburg observa que esses vestígios da representação da serpente concedem a ela o caráter de "símbolo internacional" para respostas do mundo, a saber: "A serpente, é, justamente, um símbolo internacional para responder à questão: de onde vêm a devastação elementar, a morte e o sofrimento do mundo?" (WARBURG, 2015, p. 248-249, grifo nosso).

A ideia da figura internacional corresponde, no interior da produção intelectual warburguiana, as imagens que se configuram como vestígios e são transmitidos de culturas do passado para o presente. $\mathrm{O}$ que autor nomeia como Antiguidade pagã dos Pueblos e a Antiguidade clássica contribui para a interpretação da cultura num sentido relacional e complexo, dado que, problematiza os limites de temporalidade e territorialidade na produção e difusão cultural.

Pode-se dizer que a teoria da cultura de Warburg inova ao repensar os vestígios sejam eles na produção de imagens durante o Renascimento ou no estudo antropológico do ritual da serpente do Pueblos. De fato, a Nachleben da Antiguidade, seguindo os argumentos de Warburg destacados até então, aparecem, novamente, vivas. A vida 
póstuma desses vestígios culturais, mesmo que de origem controversa, serve para os propósitos de historiadores da cultura comprometidos em pensarem o trânsito cultural, a difusão de símbolos e os desdobramentos de uma teoria da cultura despreocupadas com limites da ciência especializada moderna. Como já foi mencionado anteriormente, o interesse pelo vestígio e sua sobrevivência na cultura, sustenta a reflexão de Warburg da transmissão da Antiguidade nos tempos ulteriores.

\section{Considerações finais: devoção pelo detalhe.}

Ao longo de todo estudo procurou-se destacar um retrato da produção intelectual de Aby Warburg privilegiando a reflexão sobre os vestígios e a continuidade da cultura na história. Os ensaios escolhidos para analisar a questão proposta ilustram que o problema teórico circunscrito na concepção de vida póstuma ou sobrevivência das imagens da Antiguidade permaneceram como uma questão fundante para a teoria da cultura de Warburg ao longo de toda sua atividade intelectual. Dessa forma, a argumentação geral desse artigo sugere que nas entrelinhas das ideias de Warburg sobre a presença da Antiguidade no Renascimento ou na tradição bíblica há um elemento anterior que propicia a transmissão de símbolos e imagens compartilhados socialmente. Seguindo o passo de Warburg, o elemento estruturador da cultura seria a memória social. Entretanto, como privilegiamos uma reflexão mais próxima dos contornos teóricos da ciência da cultura em sua razão metodológica não adentramos a questão mencionada com mais profundidade, ratificando unicamente o modo como a questão dos vestígios e da continuidade histórica das imagens sustentam uma teoria da cultura warburguiana.

Sob o ponto de vista da teoria da cultura de Warburg, retomamos a importância do estudo da imagem antropologicamente 
orientada, isto é, uma investigação da arte, da representação e da simbologia que admite o potencial heurístico de outras ciências para a investigação da arte. Como se procurou mostrar, torna-se uma imagem difícil, situar a produção intelectual de Warburg, em virtude de sua atividade como "historiador da arte" abastecer e reabastecer outras tantas áreas do saber acadêmico. Em sua forma mais radical, Agamben parece ter melhor sintetizado a produção intelectual inovadora de Warburg ao nomeá-la como o pioneiro de uma ciência sem nome. É o que Wind atenta-nos ao evocar que, a busca incessante de Warburg pelas inter-relações, leva seu objeto de estudo para uma categoria tão abrangente que seus estudos contribuem desde a investigação estética até a filosofia da história, pois, ele sempre pensou a expressão artística como unidade com a imagem, poesia, religião, ritual e elemento vital da humanidade (WIND, 1931, p. 77-79). Lissovsky, por sua vez, destaca que as problematizações intelectuais de Warburg o levaram, em oposição a historiografia da arte estetizante de seu tempo, a recorrer a inúmeras fontes de arquivo para suas investigações, dando início a pesquisas heterodoxas que transitavam entre a antropologia e história da arte (LISSOVSKY, 2014, p. 307-308).

Entre a pluralidade de objetos que compõem a herança crítica de Warburg, gostaríamos, para enfim finalizar este ensaio, levantar um elemento essencial para o estudo da arte através dos vestígios e suas continuidades. Trata-se da questão do detalhe nas imagens. É o olhar direcionado para aquilo que não está na aparência, ou seja, não disposto na superfície. $O$ detalhe subsidia o olhar warburguiano para a compreensão da continuidade da Antiguidade. Lembra-nos autor no final do ensaio sobre a relação entre a Antiguidade e o Renascimento italiano: "Na 'grande' arte autônoma, o domínio artístico das formas acessórias dotadas de dinamismo vem afastar e tomar o lugar da imagem 
de uma situação dinâmica que foi de fato observada em detalhe." (WARBURG, 2015, p. 85).

Considerando o argumento defendido até então, identifica-se de imediato a importância da valorização teórica do detalhe, posto que, informado por ele, Warburg, pôde reconhecer os símbolos que permaneceram como elementos constituintes da expressão artística. Entre a Antiguidade e a Renascença, Warburg encontrou uma ponte, a saber, a sobrevivência da imagem. A busca pelo detalhe representa para a teoria da cultura de Warburg a substância viva que sustenta a existência do presente. Daí a importância da ideia de vestígios e continuidade que se caracterizam somente a partir da existência de algo que, em essência, sobrevive na história.

\section{NOTA:}

As imagens utilizadas neste ensaio foram retiradas do Banco comparativo de Imagens- Warburg, com sítio virtual administrado pelo Centro de História da Arte e Arqueologia - CHAA da Universidade Estadual de Campinas - UNICAMP, com exceção da imagem intitulada Serpente como relâmpago, obtida na publicação em língua inglesa do ensaio Images from the region of the Pueblo Indians of North America de Aby Warburg.

\section{REFERÊNCIAS}

AGAMBEN, Giorgio. Aby Warburg e a ciência sem nome. In: A potência do pensamento - Ensaios e conferências. Belo Horizonte: Autêntica Editora, 2015. p. 111-131.

DIDI-HUBERMAN, Georges. La imagen superviviente - Historia del arte y tiempo de los fantasmas según Aby Warburg. Madrid. Abada Editores. 2009. 
Dialetik des Monstrums: Aby Warburg and the symptom paradigm. Art History, vol. 24, N. 5, November 2011. p. 621-645.

GINZBURG, Carlo. De A. Warburg a E. H. Gombrich: Notas sobre um problema de método. In: . Mitos, emblemas, sinais: morfologia e história. São Paulo: Companhia das Letras, 1989. p. 41-94.

GOMBRICH, E. H. Aby Warburg: His Aims and Methods: An Anniversary Lecture. Journal of the Warburg and Courtauld Institutes, Vol. 62, 1999, p. 268-282.

LÉVY-BRUHL, Lucien. A mentalidade primitiva. São Paulo: Editora Paulus, 2008.

LISSOVSKY, Mauricio. A vida póstuma de Aby Warburg: por que seu pensamento seduz os pesquisadores contemporâneos da imagem? Boletim do Museu Paraense Emílio Goeldi, Ciências Humanas, v. 9, n.2, 2014, p. 305-322.

MATTOS, Claudia; IMORDE, Joseph. As fotografias de Aby Warburg na América: índios, imagens e ruínas. Anuário de Literatura, Florianópolis, v. 19, n.1, 2014, p. 147-157.

WARBURG, Aby. Images from the Region of the Pueblo Indians of North America. Cornell University Press, 1995.

- El renacimiento del paganismo - Aportaciones la historia cultural del Renacimiento europeo. Madrid: Editora Alianza, 2005.

- The absorption of the Expressive Values of the Past. Art in Translation. Volume 1, Issue 2, 2009, p. 273-283.

. Histórias de fantasmas para gente grande: escritos, esboços e conferências. 1. ed. São Paulo: Companhia das letras, 2015.

WIND, Edgar. O conceito de Warburg de Kulturwissenschaft e sua significação para a estética. Texto apresentando em Hamburgo em outubro de 1930 na ocasião do Quarto Congresso de estética. p. 73-90, 1931. 